\title{
CARACTERÍSTICAS FÍSICO-QUÍMICAS E SENSORIAIS DE QUEIJO TIPO CAMEMBERT PRODUZIDO COM DIFERENTES CONCENTRAÇÕES DE ESPOROS
}

\section{EVALUATION OF PHYSICO-CHEMICAL AND SENSORY CHARACTERISTICS OF CAMEMBERT CHEESE PRODUCED WITH DIFFERENT SPORES CONCENTRATIONS}

\author{
Cláudia Andréia Gräff ${ }^{1,}$ Daiana Maísa Heissler Kerwald², \\ Daniel Neutzling Lehn ${ }^{3}$, Claucia Fernanda Volken de Souza ${ }^{4}$ \\ ${ }^{1}$ Centro Universitário Univates - UNIVATES - Lajeado - Brasil claudiagraff@ univates.br \\ ${ }^{2}$ Centro Universitário Univates - UNIVATES - Lajeado - Brasil dmheissler@universo.univates.br \\ ${ }^{3}$ Centro Universitário Univates - UNIVATES - Lajeado - Brasil lehn@ univates.br \\ ${ }^{4}$ Centro Universitário Univates - UNIVATES - Lajeado - Brasil claucia@ univates.br
}

\section{Resumo}

O queijo tipo Camembert diferencia-se pela utilização do mofo branco Penicillium camemberti para o desenvolvimento de características sensoriais particulares durante o período de maturação. A literatura é vasta em relação aos estudos sobre as transformações bioquímicas que ocorrem na maturação, bem como em relação ao consórcio de outros micro-organismos com P. camemberti, no entanto são escassas as informações sobre a concentração do mofo aplicado no queijo. $O$ objetivo deste trabalho foi avaliar as características físico-químicas e sensoriais de queijo tipo Camembert no décimo dia de maturação produzido com leite tipo $C$ em escala laboratorial utilizando diferentes concentrações de esporos no inóculo aplicado por borrifamento na superfície dos queijos. Os resultados demonstraram diferenças significativas entre as características sensoriais das amostras de queijo e pode-se identificar relação entre a composição físico-química dos queijos, especialmente o teor de umidade, com os atributos sensoriais avaliados.

Palavras-chave: lácteos; Penicillium; maturação; biotecnologia.

\section{Introdução}

O gênero Penicillium é um dos mais importantes dos fungos filamentosos, algumas espécies são utilizadas na área farmacêutica e outras na produção de alimentos, principalmente de queijos (CLEMMENSEN et al., 2007). Esses fungos filamentosos se reproduzem através da esporulação assexuada, sendo os esporos também denominados de conídios. O micélio cresce de forma que as colônias se sobrepõem durante o crescimento; simultaneamente ocorre a propagação do micélio 
vegetativo, a formação dos conidióforos e a esporulação, ou seja, cada conídio liberado forma um novo micélio, por isso a propagação é rápida. Esta propriedade torna propícia a utilização deste fungo na produção de queijos (VIEIRA, 2002; KRASNIEWSKI et al., 2006).

O fungo filamentoso da espécie Penicillium camemberti é empregado como cultura starter ou iniciadora no processo de elaboração do queijo Camembert. Um queijo fino de alto valor agregado, com massa interna cremosa e casca totalmente coberta pelo mofo branco P. camemberti, que desenvolve suas características na maturação em temperatura entre 10 e $16{ }^{\circ} \mathrm{C}$, normalmente após 10 dias, quando então estará pronto para consumo (CODEX ALIMENTARIUS, 1973; DUTRA e MUNK, 2002). Seu teor de umidade entre 45 e 55\% é fator determinante para proporcionar o desenvolvimento da textura do queijo, além do curto prazo de validade do produto (ADDA et al., 1982).

As propriedades sensoriais dos alimentos são fundamentais para a escolha de compra pelos consumidores, e neste contexto a análise sensorial destaca-se como uma importante ferramenta para determinar a aceitação de queijos (LE QUÉRÉ, 2004). O desenvolvimento das características sensoriais destes produtos é um processo complexo no qual os principais componentes do leite lactose, proteína e gordura - durante o período de maturação sofrem transformações bioquímicas por ação das enzimas presentes no meio. Assim, após essas reações a massa compacta do queijo adquire corpo, textura, sabor e aroma. $\mathrm{O}$ metabolismo do fungo filamentoso $P$. camemberti produz enzimas proteolíticas que promovem a maturação do queijo da superfície para o centro da massa, resultando em odor amoniacal e ligeiro aumento do $\mathrm{pH}$ após extenso período de maturação (PERRY, 2004; DUTRA e MUNCK, 2002; ALDARF et al., 2002; MCSWEENEY, 2000; KARAHADIAN e LINDSAY, 1987).

A literatura descreve diferentes métodos de cultivo do $P$. camemberti para induzir a esporulação (KIM et al., 2010; KRASNIEWSKI et al., 2006; BOCKELMANN, 1999; NIELSEN et al., 1998), podendo alcançar a produção de $10^{8}$ esporos/g de meio sólido no sexto dia, conforme Boualem et al. (2008). O cultivo do $P$. camemberti na indústria queijeira é realizado em meio sólido acondicionado em garrafas Roux (KRASNIEWSKI et al., 2006) e os esporos podem ser inoculados diretamente no leite (BOUALEM et al., 2008; DUTRA e MUNCK, 2002), aplicados por pulverização na superfície do queijo após a salga (KRASNIEWSKI et al., 2006; SCOTT, 1991) ou misturados na salmoura (SPINNLER e GRIPON, 2004; KARAHADIAN e LINDSAY, 1987) sendo recomendada a concentração de $10^{6}-10^{7}$ esporos/mL na produção de queijos brancos (PHILIPP e PEDERSEN, 1988).

O monitoramento da biomassa fúngica e o controle do crescimento do fungo são fatores fundamentais na manufatura de queijos macios, a fim de padronizar a qualidade do produto 
(ALDARF et al., 2002). O crescimento excessivo do $P$. camemberti pode causar amargor e absorção da umidade da massa do queijo resultando num produto mais seco, e em caso de desenvolvimento insuficiente do fungo a maturação não ocorre de forma adequada (GRIPON, 2002; DAIRY AUSTRALIAN, 2011). Além disso, a quantificação do micro-organismo permite relacionar as alterações microbiológicas e bioquímicas durante a maturação (LE DRÉAN et al., 2010).

A otimização do procedimento de aplicação do fungo na superfície do queijo é indispensável para obtenção de um produto final padronizado e adequado quanto às características sensoriais. Assim, o objetivo deste trabalho foi avaliar as características físico-químicas e sensoriais de queijo tipo Camembert no décimo dia de maturação produzido com diferentes concentrações de esporos do fungo $P$. camemberti no inóculo empregado como cultura iniciadora na elaboração do produto.

\section{Material e métodos}

Micro-organismo e condições de cultivo

Utilizou-se o micro-organismo Penicillium camemberti referência IMI285506 do Instituto André Tosello. Inoculou-se na superfície do meio Ágar Batata Dextrose em garrafa Roux e armazenou-se a $25^{\circ} \mathrm{C}$.

\section{Coleta e contagem de esporos}

Preparou-se a suspensão de esporos adaptando o método descrito por Salomão (2002). Realizou-se a quantificação dos esporos pelo método de contagem por microscopia com auxílio da câmara de Neubauer, conforme descrito por Rouge (2002). Ajustou-se o volume da suspensão para uma concentração final de $10^{7}$ esporos/mL para produção dos queijos.

\section{Produção dos queijos tipo Camembert}

Os queijos foram produzidos em escala laboratorial de acordo com o método de Dutra e Munck (2002) adaptado. Utilizou-se leite pasteurizado tipo C e aplicou-se a suspensão de esporos por borrifamento na superfície. Conduziu-se a maturação em câmara climatizada por 10 dias a temperatura entre 10 e $16^{\circ} \mathrm{C}$ e umidade relativa $>85 \%$. 
Partindo da suspensão com $10^{7}$ esporos/mL foram realizadas as diluições para obter os inóculos com concentrações de $10^{6}$ a $10^{3}$ esporos/mL de $P$. camemberti para aplicar nos queijos produzidos, a fim de avaliar o efeito destas diferentes concentrações no desenvolvimento da cobertura superficial e nas características físico-químicas e sensoriais dos queijos.

As amostras de queijo elaboradas com diferentes concentrações de esporos no inóculo foram identificadas de acordo com a Tabela 1.

Tabela 1 - Identificação das amostras de queijo tipo Camembert elaboradas com diferentes concentrações de

\begin{tabular}{cc}
\multicolumn{2}{c}{ esporos no inóculo } \\
\hline Amostra & Esporos/mL \\
\hline A & $10^{7}$ \\
B & $10^{6}$ \\
C & $10^{5}$ \\
D & $10^{4}$ \\
E & $10^{3}$ \\
\hline
\end{tabular}

Espessura do micélio (mofo)

Mediu-se a espessura do micélio sobre a superfície dos queijos no décimo dia de maturação de acordo com Hermann et al. (2010) e Silva et al. (2010). Cunhas de cada queijo foram retiradas para realizar as medidas da altura $(\mathrm{em} \mathrm{cm})$ da cobertura branca sobre o queijo, que corresponde à espessura atingida pelo micélio do fungo $P$. camemberti em cada amostra.

\section{Composição físico-química}

Analisaram-se as características físico-químicas do leite empregado como matéria-prima, do soro obtido e dos queijos elaborados com diferentes concentrações de esporos no inóculo. Uma amostra comercial de queijo tipo Camembert (genericamente identificada como amostra F) também foi analisada.

Os teores de umidade, gordura, proteína, cinzas, lactose, extrato seco total (EST) foram avaliadas de acordo com os métodos descritos em Brasil (2006). O cálculo da gordura no extrato seco (GES) realizado de acordo com Spambato et al. (2000). 


\section{Análise sensorial dos queijos tipo Camembert}

A avaliação sensorial dos produtos foi realizada por 30 provadores não treinados, recrutados entre estudantes e funcionários da Univates, sendo 7 homens e 23 mulheres, com idades entre 20 e 50 anos. As amostras em porções padronizadas (aproximadamente $5 \mathrm{~g}$ ) foram codificadas com números aleatórios de três dígitos e apresentadas aos provadores de forma balanceada e aleatorizada. Junto com as amostras foi servida água mineral a temperatura ambiente para limpeza do palato e a ficha do teste contendo uma escala hedônica estruturada de nove pontos, variando de 1 “desgostei muitíssimo” a 9 "gostei muitíssimo". A análise sensorial, através do teste de aceitação, avaliou a preferência em relação aos atributos aparência, sabor, textura e impressão global do produto. Para avaliar a intenção de compra utilizou-se a escala de cinco pontos variando de 1 “certamente não compraria" a 5 "certamente compraria". Para determinar a aceitabilidade dos produtos calculou-se a frequência relativa das notas atribuídas pelos provadores na avaliação sensorial dos diferentes atributos e o índice de aceitabilidade das amostras de queijo tipo Camembert, conforme Dessimoni-Pinto et al. (2010).

O presente trabalho foi aprovado pelo Comitê de Ética em Pesquisa (COEP) da Univates sob o registro número $\mathrm{N}^{\circ} 056 / 11$.

Os resultados das análises sensoriais dos queijos tipo Camembert elaborados com diferentes concentrações de esporos foram avaliados pela Análise de Variância (ANOVA) e verificada a significância dos modelos pelo teste F. Nos modelos significativos, as médias foram comparadas entre si pelo teste de Tukey, ao nível de 5\% de significância, utilizando o software Statistica® versão 7.0 .

\section{Resultados e discussão}

A Figura 1 mostra a aparência dos queijos tipo Camembert obtidos com concentrações entre $10^{3}$ a $10^{7}$ esporos $/ \mathrm{mL}$.

O desenvolvimento do mofo na superfície dos queijos foi visível a partir do $4^{\circ}$ dia de maturação. No $5^{\circ}$ dia era nítida a diferença na espessura da camada que cobria os queijos. Nesse período de maturação a concentração de $10^{3}$ esporos $/ \mathrm{mL}$ cobria parcialmente a superfície da amostra E. Já no décimo dia de maturação o fungo se desenvolveu plenamente cobrindo totalmente a superfície da amostra E. As espessuras verificadas no décimo dia de maturação do fungo $P$. camemberti nas superfícies dos queijos foram de: 0,6 cm para Amostras A e B; 0,4 cm para Amostras C e E; e 0,5 cm para Amostra D. De acordo com Gripon (2002), após 6 a 7 dias da 
produção do queijo é visível a olho nu o desenvolvimento do $P$. camemberti e dependendo da densidade do fungo presente, cobre totalmente a superfície entre o $9^{\circ}$ e $10^{\circ}$ dia de maturação.

Figura 1 - Aparência dos queijos tipo Camembert obtidos com diferentes concentrações de esporos no inóculo
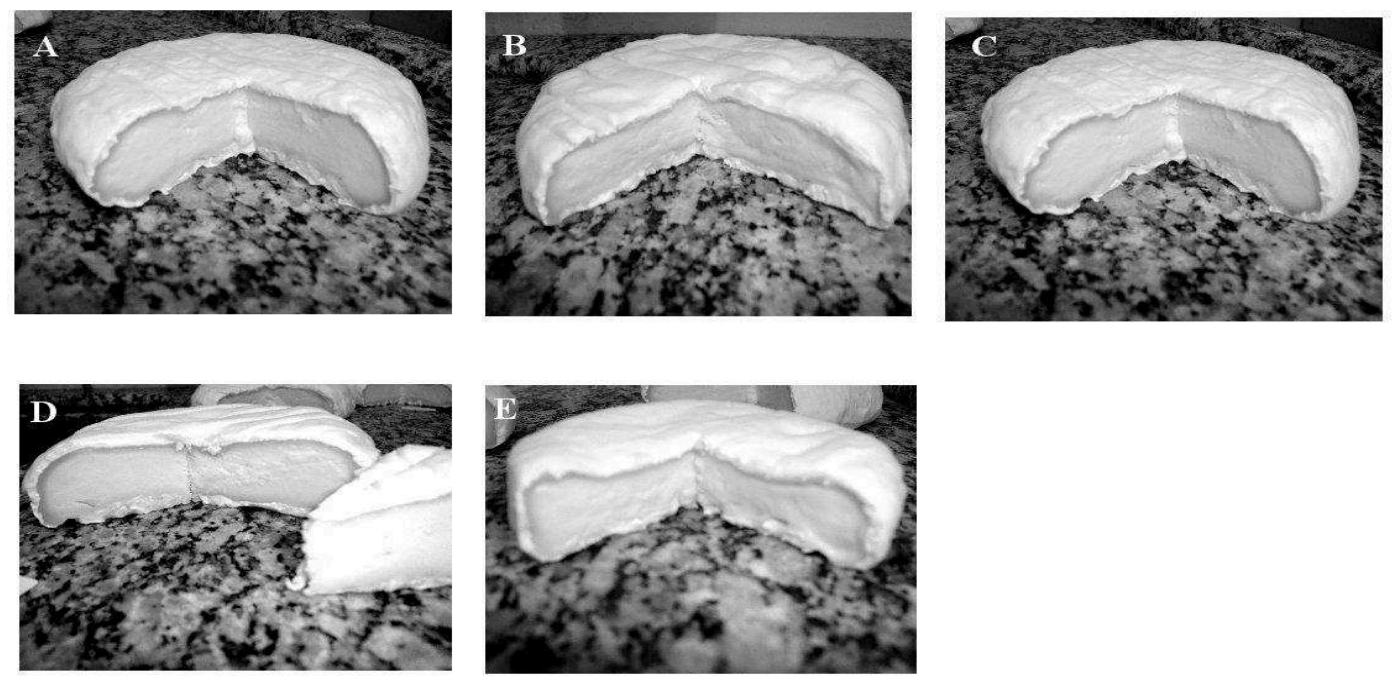

(A) Amostra - $10^{7}$ esporos $/ \mathrm{mL}$; (B) Amostra B - $10^{6}$ esporos $/ \mathrm{mL}$; (C) Amostra C - 10 esporos $/ \mathrm{mL}$; (D) Amostra D - 10 $0^{4}$ esporos $/ \mathrm{mL}$; e (E) Amostra E $-10^{3}$ esporos $/ \mathrm{mL}$.

A Tabela 2 apresenta os resultados analíticos da composição físico-química em base úmida do leite, do soro obtido na produção dos queijos, dos queijos após 10 dias de maturação e do queijo comercial.

Tabela 2 - Resultados (em \%) das análises físico-químicas do leite empregado como matéria-prima, do soro e queijos tipo Camembert obtidos no décimo dia de maturação e da amostra comercial

\begin{tabular}{cccccccc}
\hline Amostra & Umidade & Gordura & Proteína & Cinzas & Lactose & EST & GES \\
\hline Leite & $88,6 \pm 0,09$ & $3,4 \pm 0,10$ & $3,2 \pm 0,07$ & $0,7 \pm 0,00$ & 4,1 & 11,4 & - \\
Soro & $93,6 \pm 0,10$ & $0,2 \pm 0,00$ & $0,9 \pm 0,05$ & $0,7 \pm 0,00$ & 4,3 & 6,4 & - \\
A & $41,3 \pm 0,17$ & $29,1 \pm 0,20$ & $23,0 \pm 0,13$ & $2,3 \pm 0,05$ & 0 & 58,7 & 49,6 \\
B & $54,3 \pm 0,24$ & $22,0 \pm 0,12$ & $16,2 \pm 0,12$ & $3,0 \pm 0,07$ & 0 & 45,7 & 48,1 \\
C & $38,7 \pm 0,25$ & $32,1 \pm 0,14$ & $20,5 \pm 0,15$ & $2,4 \pm 0,03$ & 0 & 61,3 & 52,4 \\
D & $41,4 \pm 0,20$ & $26,1 \pm 0,19$ & $22,2 \pm 0,11$ & $2,3 \pm 0,06$ & 0 & 58,6 & 44,5 \\
E & $49,6 \pm 0,18$ & $25,2 \pm 0,10$ & $15,4 \pm 0,15$ & $3,1 \pm 0,07$ & 0 & 50,4 & 50,0 \\
F & $43,7 \pm 0,24$ & $30,4 \pm 0,20$ & $20,8 \pm 0,11$ & $3,4 \pm 0,04$ & 0 & 56,3 & 54,0 \\
\hline
\end{tabular}

O rendimento da produção dos queijos pode ser observado através dos resultados de gordura, de proteína e de lactose no leite e no soro. Obteve-se 120 g de queijo para cada litro de 
leite utilizado e de acordo com Dutra e Munck (2002) o rendimento médio na fabricação do queijo Camembert é de aproximadamente $2 \mathrm{~L}$ de leite para 1 forma de queijo de $230 \mathrm{~g}$, ou seja, $115 \mathrm{~g} / \mathrm{L}$.

O teor de sais minerais no soro está relacionado à adição de cloreto de cálcio na etapa de coagulação, já nas amostras de queijos a etapa da salga pode influenciar no teor de matéria mineral. Os resultados de cinzas obtidos para as amostras de queijos mostraram-se inferiores aos apresentados pela Usda (2011), ou seja, média 3,7 $\pm 0,14$.

Quanto à composição química dos queijos destaca-se a diferença no teor de umidade, que variou de 38,7 a 54,3 g/100 g, comportamento que influencia na concentração dos demais componentes. Entre os queijos tipo Camembert elaborados, a amostra C seguida das amostras A e D apresentaram teores de umidade inferiores a faixa de queijos de alta umidade (46,0 a 54,9\%) enquadrando-se como queijos de média umidade (36,0 a 45,9\%), conforme Brasil (1996). Os menores teores de umidade das amostras A, C e D devem-se provavelmente a uma dessoragem excessiva durante o processo de fabricação. As mesmas amostras consequentemente apresentaram os maiores valores de GES. Os queijos tipo Camembert produzidos no Brasil, de acordo com Dutra e Munck (2002), possuem um teor de umidade menor em relação aos produzidos na Europa, pois é uma característica mais adequada ao clima tropical conferindo uma consistência um pouco mais firme e proporcionando durabilidade maior ao queijo. A variação no teor de umidade não interferiu no desenvolvimento dos esporos visto que a partir da avaliação visual no $5^{\circ}$ dia de maturação observou-se o desenvolvimento proporcional do mofo da maior para a menor concentração aplicada nos queijos.

O padrão para queijo Camembert de acordo com o Codex Alimentarius (1973) é de no mínimo 30\% de GES e sem restrição para máximo, tendo como referência um nível de 45 a $55 \%$ de GES. De acordo com os resultados da Tabela 2, observa-se que todas as amostras enquadram-se na faixa de referência, com exceção da amostra $\mathrm{D}$ que apresentou-se pouco abaixo. A amostra $\mathrm{C}$ foi a que apresentou teor de GES mais próximo da amostra F (comercial). O teor de GES das amostras com 10 dias de maturação elaboradas e analisadas no presente de trabalho variou de 44,5 a 52,4\%. Resultados semelhantes são descritos na literatura para queijo Camembert. Lima et al. (2010) analisaram queijos Camembert em diferentes tempos de maturação e obtiveram $44 \%$ de GES em queijo maturado por 14 dias. Já, Dias (2007) em seu trabalho comparou a influência de $G$. candidum nas características do queijo Camembert e obteve $48 \%$ de GES no $1^{\circ}$ dia de maturação.

Conforme dados de composição de alimentos da Usda (2011), o queijo Camembert apresenta teores médios de 19,8\% de proteína, 24,3\% de gordura e 51,8\% de umidade. De acordo com esta referência as amostras B e E apresentaram teores protéicos inferiores. A amostra B apresentou resultado inferior em relação ao teor de matéria gorda, as demais amostras apresentaram 
valores semelhantes ou superiores. Esta diferença deve-se ao teor de umidade que apresentou variação entre as amostras. Resultados similares para proteína e gordura foram encontrados por Lima et al. (2010) que ao analisarem amostras de queijo Camembert no $14^{\circ}$ dia de maturação verificaram 21,6\% de proteína e $23 \%$ de gordura, e por Dias (2007) que no $1^{\circ}$ dia de maturação determinou teores de $17,5 \%$ e $24 \%$ para proteína e gordura, respectivamente. Linton et al. (2008) elaboraram queijo Camembert com leites cru e submetido a pressão e obtiveram, respectivamente, $17,3 \%$ e 16,6\% de teor protéico no produto com 14 dias de maturação.

A Tabela 3 apresenta as médias com desvio padrão dos resultados da avaliação sensorial dos atributos aparência, sabor, textura e impressão global dos queijos tipo Camembert, no décimo dia de maturação, elaborados com diferentes concentrações de esporos no inóculo.

Tabela 3 - Resultados da avaliação sensorial no décimo dia de maturação das amostras de queijo tipo Camembert elaboradas com diferentes concentrações de esporos no inóculo

\begin{tabular}{cccccc}
\hline Atributo/Amostra & $\mathbf{A}$ & $\mathbf{B}$ & $\mathbf{C}$ & $\mathbf{D}$ & $\mathbf{E}$ \\
\hline Aparência & $7,2 \pm 1,21^{\mathrm{a}}$ & $6,2 \pm 2,16^{\mathrm{b}}$ & $7,4 \pm 1,30^{\mathrm{a}}$ & $7,5 \pm 1,17^{\mathrm{a}}$ & $6,8 \pm 2,15^{\mathrm{ab}}$ \\
Sabor & $7,0 \pm 1,30^{\mathrm{ab}}$ & $6,3 \pm 2,02^{\mathrm{b}}$ & $7,3 \pm 1,28^{\mathrm{a}}$ & $7,2 \pm 1,04^{\mathrm{ab}}$ & $6,9 \pm 1,92^{\mathrm{ab}}$ \\
Textura & $7,2 \pm 1,19^{\mathrm{ab}}$ & $6,6 \pm 2,06^{\mathrm{b}}$ & $7,2 \pm 1,45^{\mathrm{ab}}$ & $7,7 \pm 1,15^{\mathrm{a}}$ & $6,9 \pm 2,22^{\mathrm{ab}}$ \\
Impressão global & $7,2 \pm 1,06^{\mathrm{ab}}$ & $6,6 \pm 1,94^{\mathrm{b}}$ & $7,4 \pm 1,22^{\mathrm{ab}}$ & $7,5 \pm 1,11^{\mathrm{a}}$ & $6,9 \pm 2,06^{\mathrm{ab}}$ \\
\hline
\end{tabular}

${ }^{\mathrm{ab}}$ Médias com letras diferentes, na mesma linha, apresentam diferença significativa entre si $(\mathrm{P} \leq 0,05)$, conforme resultado do teste de Tukey.

As amostras D e C elaboradas com $10^{4}$ esporos $/ \mathrm{mL}$ e $10^{5}$ esporos $/ \mathrm{mL}$, respectivamente, foram as que apresentaram as maiores médias na avaliação sensorial dos atributos avaliados aparência, sabor, textura e impressão global.

Já a amostra B (10 esporos $/ \mathrm{mL})$ seguida da amostra E $\left(10^{3}\right.$ esporos $\left./ \mathrm{mL}\right)$ apresentaram as menores médias em relação a todas as características sensoriais avaliadas. Com base nos resultados de umidade (Tabela 2) essas amostras são classificadas como queijo de alta umidade. Esses resultados da avaliação sensorial correlacionados com o de umidade, provavelmente são consequência dos provadores ainda não estarem habituados a consumir este tipo de queijo, mostrando também a necessidade de disseminação desta variedade.

$\mathrm{Na}$ avaliação do atributo aparência a amostra $\mathrm{B}$ foi considerada diferente $(\mathrm{P} \leq 0,05)$ das amostras A, C e D, e igual a amostra E. Quanto ao sabor, as amostras B e C apresentaram diferença significativa entre si $(\mathrm{P} \leq 0,05)$. Em relação a avaliação dos atributos textura e impressão global as amostras B e D diferiram entre si $(P \leq 0,05)$ e as demais não apresentaram diferença significativa. 
A Figura 2 apresenta a distribuição de frequência das notas obtidas pelas amostras de queijos tipo Camembert, em relação aos atributos aparência, sabor, textura e impressão global, no décimo dia de maturação e elaboradas com diferentes concentrações de esporos no inóculo.

Figura 2 - Distribuição de frequência dos atributos sensoriais avaliados no décimo dia de maturação das amostras de queijos tipo Camembert elaboradas com diferentes concentrações de esporos no inóculo

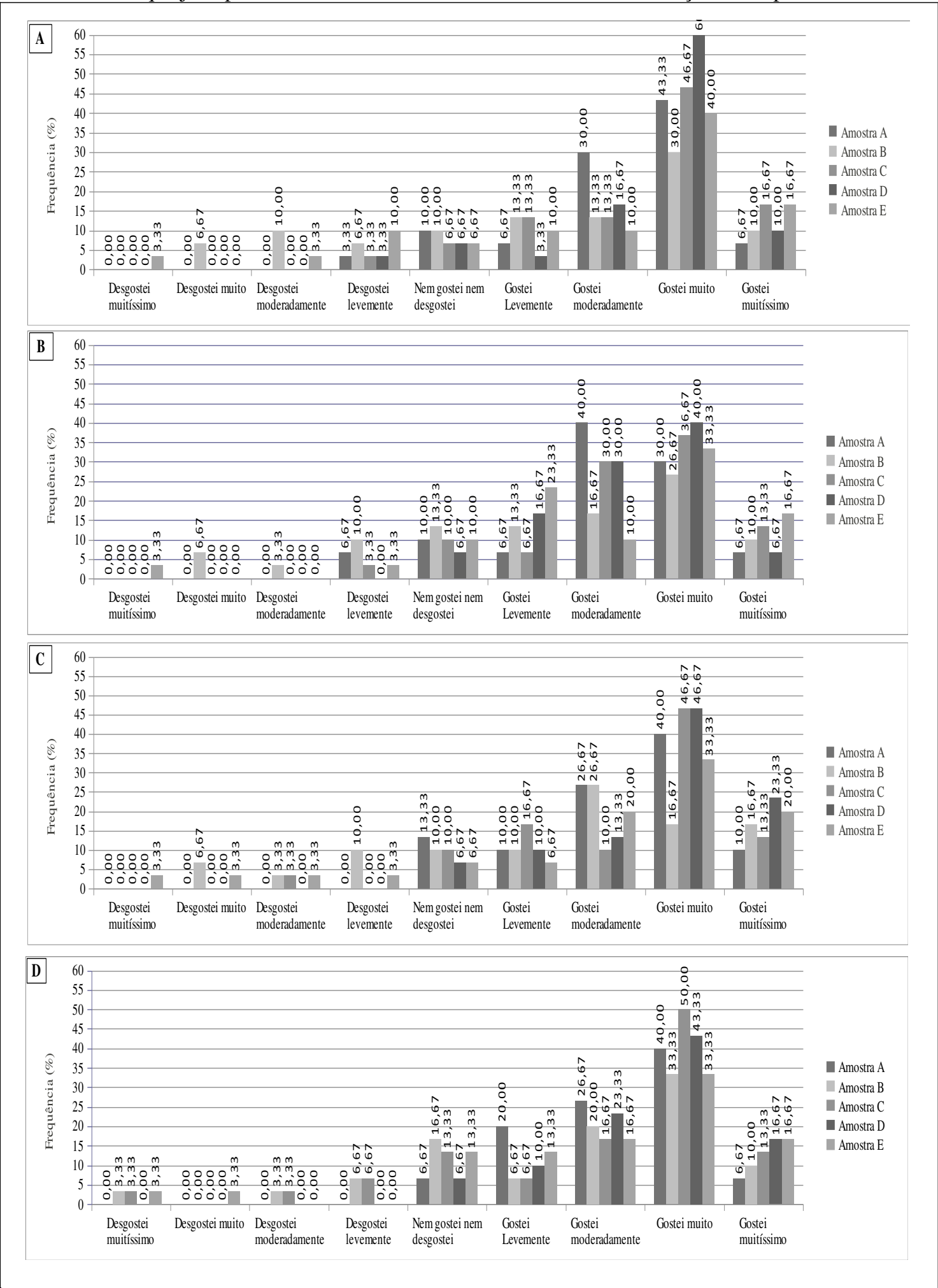

(A) Aparência; (B) Sabor; (C) Textura; e (D) Impressão global. 
A distribuição de frequência da avaliação das características sensoriais mostra um consenso entre os provadores que escolheram com maior frequência a nota 8 "gostei muito" para todas as amostras em todos os atributos, seguida da nota 7 "gostei moderadamente" para as amostras A, C e especialmente a amostra D. Resultados semelhantes foram obtidos por Dias (2007) em amostras de queijo Camembert avaliadas no trigésimo dia de maturação, cujas médias variaram de 7,30 a 8,13 para todos os atributos. Para o atributo aparência a amostra D destacou-se com $60 \%$ de frequência para a nota 8 "gostei muito". Lima et al. (2010) também verificaram que $60 \%$ dos provadores manifestaram a nota 8 "gostei muito" no teste de aceitação do queijo Camembert maturado por 31 dias.

Os resultados do índice de aceitabilidade dos atributos aparência, sabor, textura e impressão global no décimo dia de maturação das amostras de queijos tipo Camembert elaboradas com diferentes concentrações de esporos no inóculo estão apresentados na Figura 3.

Figura 3 - Índice de aceitabilidade no décimo dia de maturação dos queijos tipo Camembert elaborados com diferentes concentrações de esporos no inóculo

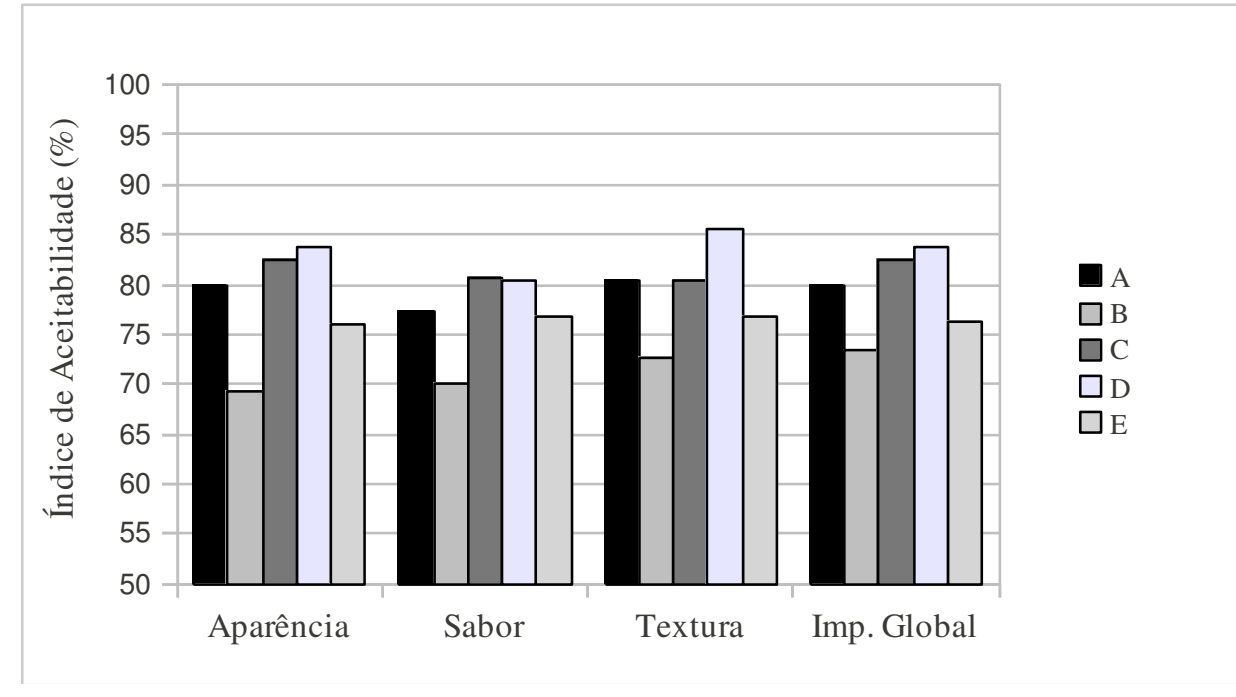

O índice de aceitabilidade de todos os atributos avaliados foi menor para as amostras B e E. Relacionando os resultados do índice de aceitação, com o teor de umidade e a concentração dos esporos no inóculo aplicado nos queijos, observou-se que o teor de umidade teve uma maior influência nas características sensoriais dos queijos com maior aceitação pelos provadores. Pois, as amostras E e B que apresentaram os maiores teores de umidade foram maturadas com $10^{3}$ (menor concentração de esporos) e $10^{6}$ esporos/mL (uma das maiores concentrações de esporos aplicadas), respectivamente, sendo assim pode-se afirmar que ambas tiveram condições semelhantes para o desenvolvimento do mofo e mesmo assim foram as menos aceitas pelos provadores. 
Segundo Dessimoni-Pinto (2010) para que o produto seja considerado aceito por suas propriedades sensoriais é importante que obtenha um índice de aceitabilidade de no mínimo $70 \%$. Assim, a avaliação sensorial realizada nesse estudo demonstrou que as amostras A, C, D e E apresentam potencial para comercialização.

A Figura 4 apresenta a intenção de compra das amostras de queijo tipo Camembert elaboradas com diferentes concentrações de esporos no inóculo.

Figura 4 - Intenção de compra dos queijos tipo Camembert elaborados com diferentes concentrações de esporos no inóculo

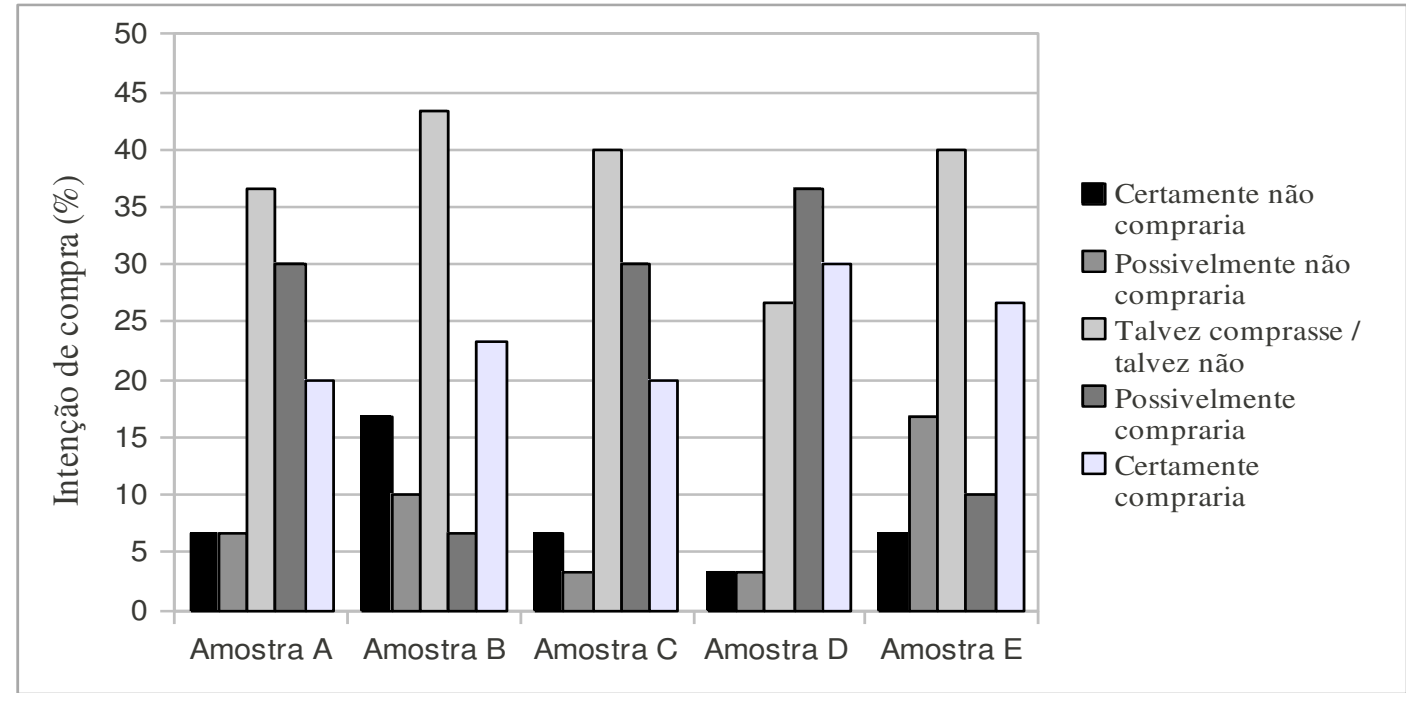

A amostra B foi a que apresentou maior número de menções para a opção "certamente não compraria". As amostras B e E apresentaram 27 e 23\%, respectivamente, de menções negativas em relação a intenção de compra. Já a amostra D seguida das amostras A e C apresentaram 67 e 50\%, respectivamente, de menções positivas em relação a intenção de compra. As altas frequências para a opção "talvez compraria/talvez não compraria" podem ser devido aos provadores não terem o hábito de consumo desta variedade de queijo, demonstrando inclusive uma lacuna a ser preenchida pela indústria do setor.

As médias dos resultados de intenção de compra apresentaram-se entre 3,1 (amostra B) e 3,9 (amostra D) na escala de 1 a 5. As amostras A e C foram semelhantes com média igual a 3,5. A média 3,3 foi obtida para a amostra E sendo que ela apresentou-se semelhante estatisticamente a $\operatorname{amostra} \mathrm{B}(\mathrm{P} \leq 0,05)$.

\section{Conclusões}

Os resultados obtidos mostram que a concentração de esporos do fungo $P$. camemberti no inóculo empregado como cultura iniciadora influencia nas características sensoriais do queijo tipo 
Camembert com 10 dias de maturação. Os queijos elaborados com $10^{4}$ e $10^{5}$ esporos/mL apresentaram os melhores resultados na avaliação sensorial dos atributos aparência, sabor, textura e impressão global. Já a amostra com $10^{4}$ esporos/mL apresentou a maior frequência de menções positivas em relação a intenção de compra do produto. Em relação as características físicoquímicas, verificou-se que o teor de umidade é o que mais influencia na aceitação do queijo tipo Camembert.

\begin{abstract}
The Camembert cheese distinguished by the use of white mold Penicillium camemberti in the development of particular sensory characteristics during the maturation period. There are many studies about the biochemical transformations that occur in the aging and in relation to the consortium of other microorganisms with P. camemberti, but only scant information on the concentration applied to the mold in cheese. The objective of this study was to evaluate the physicochemical and sensory characteristics of Camembert cheese on the tenth day of maturation made with milk type $C$ in the laboratory scale using different concentrations of spores in the inoculum applied by spraying on the surface of the cheese. The results showed significant differences between the samples in terms sensory and can identify relationship between physico-chemical composition of cheeses, especially the moisture content, with sensory attributes.
\end{abstract}

Key words: dairy; Penicillium; maturation; biotechnology.

\title{
Agradecimentos
}

Os autores agradecem ao Centro Universitário Univates e à Secretaria da Ciência, Inovação e Desenvolvimento Tecnológico do Estado do Rio Grande do Sul pela concessão da bolsa de iniciação científica e auxílios financeiros.

\section{Referências}

ADDA, J.; GRIPON, J. C.; VASSAL, L. The chemistry of flavour and texture generation in cheese. Food Chemistry, London, n. 9, p. 115-129, 1982.

ALDARF, M.; FOURCADE, F.; AMRANE, A.; PRIGENT, Y. Grow model of Penicillium camembertii cultivated on a solid medium - a logistic model for substrate comsuption and metabolite product. Process Biochemistry, London, n. 38, p. 333-342, 2002.

BOCKELMANN, W.; PORTIUS, S.; LICK, S.; HELLER, K. J. Sporulation of Penicillium camemberti in submerged batch culture. Systematic and applied microbiology, Jena, n. 22, p. 479-485, 1999.

BOUALEM, K.; WACHÉ, Y.; GARMYN, D.; KARBOWIAK, T.; DURAND, A.; GERVAIS, P.; CAVIN, J.-F. Cloning and expression of genes involved in conidiation and surface properties of Penicillium camemberti grown in liquid and solid cultures. Research in Microbiology, Paris, n. 159, p. 110-117, 2008.

BRASIL. Ministério da Agricultura, Pecuária e do Abastecimento. Portaria n ${ }^{\circ}$ 146. Regulamentos Técnicos de Identidade e Qualidade dos Produtos Lácteos. Brasília, Diário Oficial da União, 1996. Disponível em: $<$ http://extranet.agricultura.gov.br/sislegis/action/detalhaAto.do?method=consultarLegislacaoFederal>. Acesso em 13 dez. 2011.

, Instrução Normativa n ${ }^{\circ}$ 68. Oficializa os Métodos Analíticos Oficiais Físico-Químicos, para Controle de Leite e produtos lácteos. Brasília, Diário Oficial da União, 2006. 
<http://extranet.agricultura.gov.br/sislegis/action/detalhaAto.do?method=consultarLegislacaoFederal>. Acesso em 16 nov. 2011.

CLEMMENSEN, L. H.; HANSEN, M. E.; FRISVAD, J. C.; ERSBOLL, B. K. A method for comparison of growth media in objective identification of Penicillium based on multi-spectral imaging. Journal of Microbiological Methods, Amsterdam, n. 69, p. 249 - 255, 2007.

CODEX Alimentarius. Codex standard for Camembert. CODEX STAN 276 (1973). Disponível em: <http://www.codexalimentarius.net/download/standards/218/CXS_276e.pdf>. Acesso em: 16 nov. 2011.

DAIRY Australian. White mould cheese. Disponível em: <http://www.dairyaustralia.com.au/Dairy-food-andrecipes/Dairy-Products/Cheese/Types-of-Cheese/White-Mould-Cheese.aspx> Acesso em 30 Nov 2011.

DESSIMONI-PINTO, N. A. V.; SILVA, V. M.; BATISTA, A. G.; VIEIRA, G.; SOUZA, C. R.; DUMONT, P. V.; SANTOS, G. K. M. Características físico-químicas da amêndoa de macaúba e seu aproveitamento na elaboração de barras de cereais. Alimentos e Nutrição, Araraquara, v. 21, n. 1, p. 77-84, 2010.

DIAS, G. Influência do uso de Geotrichum candidum nas características físico-químicas e sensoriais do Queijo Tipo Camembert. 2007. 57p. Dissertação (Mestrado em Ciência e Tecnologia de Alimentos ) - Universidade Federal de Viçosa, Viçosa, 2007. Disponível em:

$<$ http://www.dominiopublico.gov.br/pesquisa/DetalheObraForm.do?select_action=eco_obra=131470>. Acesso em: 16 nov. 2011

DUTRA, E. R. P.; MUNCK, A. V.. Fabricação de queijos finos. Instituto Cândido Tostes, Juiz de Fora: 2002.

GRIPON, J. C. Mould-Ripened Cheeses. In: Roginski H, Fuquay JW and FOX PF. Encyclopedia of Dairy Sciences, Academic Press, 2002. p. 401-406.

HERMANN, K. L.; LOVATEL, A.; HELM, C. V.; LIMA, E. A.; TAVARES, L. B. B. Avaliação da densidade micelial e da atividade de Manganês peroxidase (MnP) em fungos Basidiomicetos. Anais da Mostra Integrada de Ensino, Pesquisa e Extensão. Dynamis Revista Tecno-científica, Blumenau, v. 16, n. 2, p. 36-109, 2010.

KARAHADIAN, C.; LINDSAY, R. C. Integrated Roles of Lactate, Ammonia, and Calcium in Texture Development of Mold Surface-Ripened Cheese. Journal of Dairy Science, Champaign, v. 70, n. 5, p. 909-918, 1987. http://dx.doi.org/10.3168/jds.S0022-0302(87)80094-2

KIM, J. S.; SKINNER, M.; HATA, T.; PARKER, B. L. Effects of culture media on hydrophobicity and thermotolerance of $\mathrm{Bb}$ and $\mathrm{Ma}$ conidia, with description of a novel surfactant based hydrophobicity assay. Journal of Invertebrate Pathology, San Diego, n. 105, p. 322-328, 2010.

KRASNIEWSKI, I.; MOLIMARD, P.; FERON, G.; VERGOIGNAN, C.; DURAND, A.; CAVIN, J.-F.; COTTON, P. Impact of solid medium composition on the conidiation in Penicillium camemberti. Process Biochemistry, London, $\mathrm{n}$. 41, p. $1318-1324,2006$.

LE DRÉAN, G.; MOUNIER, J.; VASSEUR, V.; ARZUR, D.; HABRYLO, O.; BARBIER, G. Quantification of Penicillium camemberti and P. roqueforti mycelium by real-time PCR to assess their growth dynamics during ripening cheese. International Journal of Food Microbiology, Amsterdam, n. 138, p. 100-107, 2010.

LE QUÉRÉ, J. L. Cheese Flavour: Instrumental Techniques. In: Cheese: Chemistry, Physics and Microbiology. Elsevier, v. 1, p. 489-510, 2004.

LIMA, D. C.; GOULART, P. F. P.; OLIVEIRA, R. M. E. Avaliações sensorial, físico-química e microbiológica de queijo camembert em diferentes tempos de maturação. Revista do Instituto de Laticínios Cândido Tostes, Juiz de Fora, v. 65, n. 372, p. 41-46, 2010.

LiNTON, M.; MACKLE, A. B.; UPADHYAY, V. K.; KELLY, A. L.; PATTERSON, M. F. The fate of Listeria monocytogenes during the manufacture of Camembert-type cheese: A comparison between raw milk and milk treated with high hydrostatic pressure. Innovative Food Science \& Emerging Technologies, Wageningen , v. 9, n. 4, p. 423428, 2008. http://dx.doi.org/10.1016/j.ifset.2008.01.001 
MCSWEENEY, P. L. H.; SOUSA, M. J. Biochemical pathways for the production of flavour compounds in cheeses during ripening: a review. Lait, Les Ulis, n. 80, p. 293-324, 2000.

NIELSEN, M. S.; FRISVAD, J. C.; NIELSEN, P. V. Protection by fungal starters against growth and secondary metabolite production of fungal spoilers of cheese. International Journal of food microbiology, Amsterdam, n. 42, p. 91-99, 1998.

PERRY, K. S. P. Queijos: aspectos químicos, bioquímicos e microbiológicos. Química Nova, São Paulo, v. 27, n. 2, 2004.

PHILIPP, S.; PEDERSEN, P. D. Mould cultures for the food industry. Danish dairy and food industry worldwide. Odense, n. 6, p. 8-12, 1988.

ROUGE, M. Counting Cells with a Hemacytometer. 2002. In: Bowen, R. Collection and Evaluation of Semen: Introduction and Index. Disponível em:

<http://arbl.cvmbs.colostate.edu/hbooks/pathphys/reprod/semeneval/hemacytometer.html> Acesso em 16 nov. 2011.

SALOMÃO, B. C. M. Isolamento, identificação e estudo da resistência térmica de fungos filamentosos termorresistentes em produtos de frutas. 2002. 120 p. Dissertação (Mestrado em Engenharia de Alimentos) Universidade Federal de Santa Catarina, Florianópolis, 2002. Disponível em: <pgeal.paginas.ufsc.br/files/2010/09/Beatriz.pdf>. Acesso em: 03 dez. 2011.

SCOTT, R. Fabricación de queso. Zaragoza: Editora Acríbia, 1991. p. 520.

SILVA, G.; MARINO, R. H.; LOPES, M. E. G.; ALMEIDA, T. Á.; COSTA, Â. C. F.; MARTINS, M. V. G. Avaliação do potencial de degradação de fungos causadores de podridão branca. Revista Brasileira de Ciências Agrárias, Recife, v. 5, n. 2, p. 225-231, 2010. http://dx.doi.org/10.5039/agraria.v5i2a628

SPAMBATO, C. G.; ABREU, L. R.; FURTADO, M. M. Queijo Gorgonzola fabricado com leite pasteurizado por ejetor de vapor e HTST: parâmetros físico-químicos e sensoriais. Pesquisa Agropecuária Brasileira, Brasília, v. 35, n. 1, p. 191-200, 2000. http://dx.doi.org/10.1590/S0100-204X2000000100021

SPINNLER, H. E.; GRIPON, J. C. Surface Mould-ripened Cheeses. In: . Cheese: Chemistry, Physics and Microbiology. Major Cheese Groups. Elsevier, 2004. v. 2, p. 157-174. Disponível em: <http://www.sciencedirect.com/science/article/pii/S1874558X04800435>. Acesso em: 03 dez. 2011.

USDA. National Nutrient Database for Standard Reference. Release 24, Food Group: 01 Dairy and Egg Products. 2011. Disponível em: <http://www.ars.usda.gov/Services/docs.htm?docid=22112>. Acesso em: 04 Dez 2011.

VIEIRA. F. C. S.; LA SCALA, J. N.; NAHAS, E. Erro na contagem de fungos pelo método "Pour plate". Revista Ceres, Viçosa, v. 283, n. 49, p. 335-340, 2002.

Submetido em 09 out. 2012, Aceito para publicação em 23 jun. 2014, Publicado em 28 dez. 2014. 